\title{
A comparison of purposeless movements in psychiatric patients treated with antipsychotic drugs, and normal individuals
}

\author{
THOMAS RE BARNES*, MARTIN ROSSOR $\dagger$, THOMAS TRAUER \\ From the Psychiatric Research Unit University of Cambridge Clinical School, Cambridge, ${ }^{*}$ the National \\ Hospital for Nervous Diseases $†$ London, and King’s College Hospital, $¥$ London, UK
}

SUMMARY Oro-facial dyskinesia and purposeless trunk and limb movements were assessed, using a standard videotape rating technique, in 182 psychiatric patients receiving antipsychotic medication, in a second sample of 43 elderly psychiatric patients also receiving antipsychotic drugs, and 85 normal, drug-naive subjects. In both the first patient sample and the group of normal subjects, oro-facial dyskinesia was more common over 50 years of age. Statistical analysis of the data suggested that drug-induced oro-facial dyskinesia has a characteristic pattern of movement distribution significantly different from that of idiopathic oro-facial dyskinesia. The videotapes of the first patient sample and the normal subjects were viewed by a neurologist who assessed and categorised all movements. Purposeless trunk and limb movements were classified as either normal or abnormal. Normal purposeless movements were significantly more common in the drug-naive subjects. The presence of abnormal movements such as choreiform movements, dystonias and stereotypies and mannerisms was limited, almost exclusively, to the patients.

Tardive dyskinesia is a movement disorder induced by antipsychotic drugs. It is characterised by abnormal movements affecting the face, principally the tongue, lips and jaw, producing a typical picture referred to as the bucco-linguo-masticatory syndrome. ${ }^{1}$ Choreiform movements of the limbs and axial hyperkinesias are usually included within the syndrome description. However, there are a number of problems inherent in trying to assess tardive dyskinesia quantitatively and qualitatively. ${ }^{23}$ The operational diagnostic criteria used between clinical research groups vary considerably and this complicates the interpretation of results. There are also discrepancies between the rating scales used, not only regarding the number and definition of movement categories included but also their relative importance, as indicated by the scoring systems. The precise nature and distribution of abnormal movements are seldom attended to by investigators. Rather, the individual dyskinetic phenomena tend to be obscured by the use of arbitrary global categories.

Tardive dyskinesia is not specific to schizophrenic patients and has been reported in non-psychotic

Address for reprint requests: Dr TRE Barnes, Psychiatric Research Unit, Old Addenbrooke's Hospital, Trumpington St, Cambridge CB2 2QE UK psychiatric populations receiving antipsychotic drugs. ${ }^{4-9}$ In addition, a condition described as spontaneous or idiopathic oro-facial dyskinesia has been described in psychiatric inpatients, predominantly elderly, who have apparently never received antipsychotic drugs. ${ }^{5610^{-16}}$ However, as Crane ${ }^{17}$ has stated "chronicity of disease and/or institutionalisation with attendant emotional and physical deprivation", may be responsible for these abnormal movements, being a common factor in both drugtreated and non-drug-treated psychiatric inpatients. But Altrocchi ${ }^{18}$ has described two outpatient cases presenting with idiopathic or spontaneous oro-facial dyskinesia, and this condition has been observed as a relatively rare phenomenon in normal drug-free residents in old-age homes. ${ }^{519}$ Marsden and Parkes ${ }^{20}$ estimated that this condition is present in some $2 \%$ of the geriatric home population. These cases are generally considered to be phenomenologically indistinguishable from tardive dyskinesia, ${ }^{182021}$ and a similar pathophysiological basis has been suggested. ${ }^{22}$

In this study we set out to investigate the nature and distribution of semi-purposeful and purposeless spontaneous movements in psychiatric patients treated with antipsychotic drugs, compared with those observed in a control population. 


\section{Method}

The first group of subjects consisted of 182 psychiatric patients, all of whom had been receiving antipsychotic medication for at least one year. In addition, 85 drug-naive normal individuals were studied; comprising an unselected sample of surgical outpatients, plus hospital and medical school staff. Subsequently, six wards were chosen at random at a different mental hospital and a second patient group of 43 elderly, chronic psychiatric inpatients, was identified and examined. All had a case-note diagnosis of schizophrenia and all were receiving maintenance antipsychotic medication. Table 1 provides details of the demographic and clinical characteristics of the three samples. Informed consent was obtained from all subjects following explanation of the procedures involved.

A tardive dyskinesia rating tẹchnique, previously described by Barnes and Trauer, ${ }^{3}$ was employed. All patients were videotaped while engaged in a standard activity; seated and reading a piece of large-type prose as part of a simple comprehension test. For each subject the duration of purposeless movements at each of eight body sites was rated on a four-point scale, $(0=$ absent, $1=$ movement present less than half the one minute observation period, $2=$ movement present more than half the time but not continuously, $3=$ continuous movement); the criterion of severity therefore, being the proportion of the observation period that the movement was present. All tapes were rated by three independent observers, blind to whether the subjects were patients or normal controls. For each set of three ratings a single "modal" score was derived according to a method previously described. ${ }^{22}$ These modal scores, reflecting "duration" of movement, are used exclusively in the Results section.

One of us (MR), who was blind to the identity of the subjects as either patients or normal controls, viewed the videotapes and made a clinical judgement as to whether the movements observed were within the normal range or abnormal. Normal purposeless and semipurposeful movements were those considered to be acceptable for a normal population and included restlessness, fidgeting and shifting of posture. Movements which were considered to be abnormal clinically were then characterised as dystonic, choreiform, tremor, tics or stereotypies and mannerisms, according to the clinical descriptions proposed by the Research Group on Extrapyramidal Disorders of the World Federation of Neurology ${ }^{23}$ where applicable.

\section{Statistical analysis}

One aim of this study was to compare the pattern of movement distribution across body sites between two groups: the first patient sample and the normal controls. An appropriate statistical method for such a comparison is a two-way analysis of variance. Thus, this technique was used to compare the modal "duration" scores of purposeless movements on a number of body sites between the two groups. A further refinement to this analysis was necessary as the movement score variable was known to be strongly correlated with age, and our two groups of subjects were not matched on this variable. Analysis of covariance was used to adjust each subject's score on a criterion variable (duration of movement) according to its known correlation with another variable (age), before proceeding to the analysis of variance.

\section{Results}

The mean scores for duration of movement for the first group of 182 patients and the 85 normal subjects, were plotted in five age-bands for each body site, producing the "movement profiles" displayed in Figure 1. In order to reduce the five age-profiles to a single representative profile for each population, the movement scores were adjusted for age by analysis of covariance (see Method). Figure 2 displays the adjusted scores as both a graphical plot, to illustrate the distribution pattern and also, more appropriately, as a histogram. The analysis of covariance allowed examination of the independent contributions of (1) drug exposure (patients or normal subjects), (2) body site and (3) the interaction of (1) and (2) to the explanation of the total variance. All three sources have statistically significant

Table 1 Characteristics of the three study samples

\begin{tabular}{lccc}
\hline & $\begin{array}{l}\text { Patient group 1 } \\
(n=182)\end{array}$ & $\begin{array}{l}\text { Patient group 2 } \\
(n=43)\end{array}$ & $\begin{array}{l}\text { Control subjects } \\
(n=85)\end{array}$ \\
\hline $\begin{array}{l}\text { Status: } \\
\text { outpatients } \\
\text { inpatients }\end{array}$ & 120 & 0 & - \\
$\begin{array}{l}\text { Age (years) } \\
\text { range } \\
\text { median }\end{array}$ & 60 & 43 & \\
$\begin{array}{l}\text { Antipsychotic dosage* } \\
\text { range } \\
\text { median }\end{array}$ & $24-78$ & $60-89$ & $17-81$ \\
\hline
\end{tabular}

\footnotetext{
${ }^{*}$ Chlorpromazine equivalents per day. ${ }^{40-42}$
} 


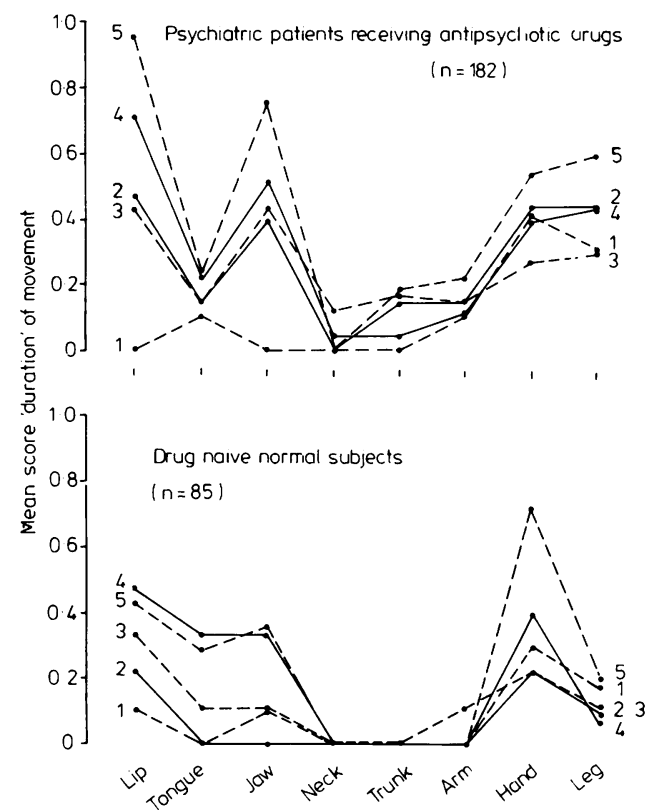

Fig 1 Mean scores for duration of purposeless movements at eight body sites, in the first group of drug-treated patients and drug-naive normal subjects

\begin{tabular}{lll}
\hline Age bands & Patients $(n)$ & Normal subjects $(n)$ \\
\hline $1=$ less than 30 years & 10 & 29 \\
$2=30-39$ years & 28 & 18 \\
$3=40-49$ years & 42 & 9 \\
$4=50-59$ years & 47 & 15 \\
$5=60$ years and over & 55 & 14 \\
\hline
\end{tabular}

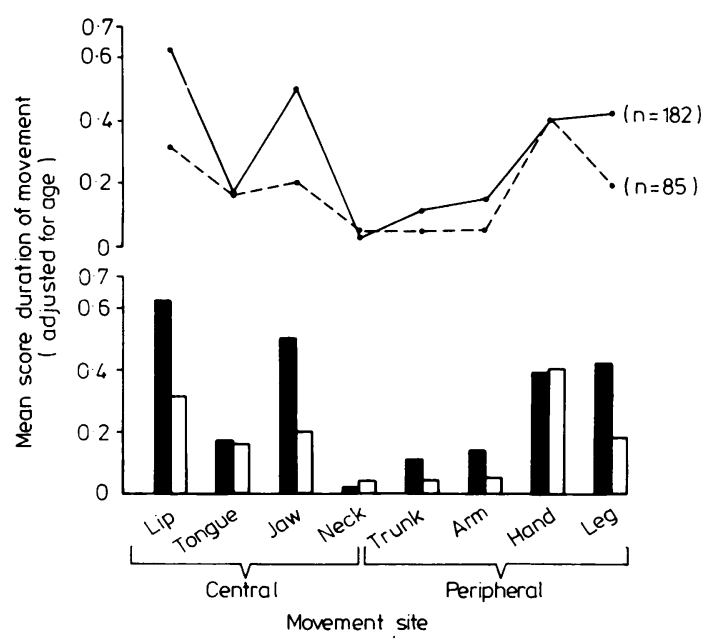

Fig 2 Age-adjusted scores for duration of purposeless movements at eight body sites, in the first group of drug-treated patients $(\mathbf{O}, \mathbf{\square})$ and the drug-naive normal subjects (๑---๑, 口) effects: patients had significantly higher movement scores than controls $(\mathrm{F}=9.7$, df $=1,1855, \mathrm{p}<$ 0.001 ); there was a significant difference in movement scores between body sites $(F=28 \cdot 4$, df $=$ $7,1855, p<0.001$ ), and, perhaps of particular interest, the interaction between body sites and the two groups of subjects was also significant $(\mathrm{F}=3 \cdot 56, \mathrm{dF}$ $=7,1855, \mathrm{p}<0.005)$. The significant interaction term indicates that the patterns of distribution of movement scores in the two groups are significantly different from each other.

The movement profiles were also analysed as two separate sub-syndromes within each group. The pattern of scores for the "central" sub-syndrome, that is, lip, tongue, jaw and neck movement, was compared between the patients and normal subjects. Using the same analysis of variance procedure, a significant difference $(F=5 \cdot 8$, df $=3,795, p<$ $0 \cdot 005$ ) was revealed. As can be seen from fig 2 , the patients were characterised by a marked predominance of lip and jaw movements compared to tongue and neck, whereas in the controls there was little difference between the scores at the four sites, although lip and jaw movement scores tended to be slightly higher than those for tongue and neck. A similar comparison of the "peripheral" subsyndrome pattern (arm, hand, leg and trunk movements) between the two populations did not reach statistical significance $(F=2 \cdot 4$, df $=3,795, p>$ 0.05 ).

In order to determine whether the movement score profile for the drug-treated patient sample was representative of such patients, and therefore reproducible in a separate patient group, a second sample, of 43 schizophrenic inpatients over 60 years old (mean age 70.0 years) was assessed using the same rating technique. Their scores were compared with those of all 55 patients in the first group who fell within the same age-range (mean age 65.5 years). The mean ages for these two samples of elderly patients were not significantly different. Figure 3 displays the mean movement scores for both populations. The two profiles appear closely aligned and this similarity is confirmed by a high rank order correlation of movement scores for the eight body sites (Spearman Rho $=0.8, \mathrm{p}<0.05$ ).

Table 2 presents the classification of movements observed in the first patient group and the normal individuals, and indicates the prevalence of each of a number of movement categories in the two samples, within four age-groups. Categories of movement that were significantly more common in one sample compared with the corresponding age-group in the other sample, using a Chi-squared test with Yates' correction, are indicated in the table. Also, within each sample, the prevalence of each movement 
Table 2 Neurologist's classification of movements, with prevalence figures for movement categories, in the furst patient sample and the sample of normal subjects

\begin{tabular}{|c|c|c|c|c|c|c|c|c|c|c|}
\hline \multirow[b]{3}{*}{ Age Bands (years) } & \multicolumn{5}{|c|}{ 1st patient sample $(n=182)$} & \multicolumn{5}{|c|}{ Normal subjects $(n=85)$} \\
\hline & \multicolumn{5}{|c|}{$n(\%)$ of age group } & \multicolumn{5}{|c|}{$n$ (\%) of age group } \\
\hline & $\begin{array}{l}<39 \\
(n=38)\end{array}$ & $\begin{array}{l}40-49 \\
(n=42)\end{array}$ & $\begin{array}{l}50-59 \\
(n=47)\end{array}$ & $\begin{array}{l}>60 \\
(n=55)\end{array}$ & $\begin{array}{l}\text { Comparison of } \\
\text { patients }<50 \text { year } \\
\text { and }>50 \text { years }\end{array}$ & $\stackrel{<39}{<(n=47)}$ & $\begin{array}{l}40-49 \\
(n=9)\end{array}$ & $\begin{array}{l}50-59 \\
(n=15)\end{array}$ & $\begin{array}{l}>60 \\
(n=14)\end{array}$ & $\begin{array}{l}\text { Comparison of } \\
\text { subjects }<50 \text { years } \\
\text { and }>50 \text { years }\end{array}$ \\
\hline $\begin{array}{l}\text { Semipurposeful or } \\
\text { purposeless normal } \\
\text { movement }\end{array}$ & $9(24)$ & $13(31)$ & $16(34)$ & $16(29)$ & NS & $22(47)$ & $3(33)$ & $9(60)$ & $9(64)$ & NS \\
\hline Oro-facial dyskinesia & $8(21) \ddagger$ & $10(24)$ & $19(40)$ & $27(49)$ & $\begin{array}{l}\text { More common in } \\
\text { patients }>50 \\
\text { years } \neq\end{array}$ & $1(2)$ & $1(11)$ & $4(26)$ & $2(14)$ & $\begin{array}{l}\text { More common in } \\
\text { subjects }>50 \\
\text { years* }\end{array}$ \\
\hline $\begin{array}{l}\text { Choreiforms } \\
\text { movements }\end{array}$ & $4(10)$ & $4(9)$ & $9(19)$ & $16(29)$ & $\begin{array}{l}\text { More common in } \\
\text { patients }>50\end{array}$ & 0 & 0 & 0 & $2(14)$ & NS \\
\hline $\begin{array}{l}\text { Sterotypy/mannerism } \\
\text { Dystonia } \\
\text { Tremor } \\
\text { Tic } \\
\text { No significant } \\
\text { movement }\end{array}$ & $\begin{array}{l}2(5) \\
3(8) \\
0 \\
0 \\
17(45)\end{array}$ & $\begin{array}{c}3(7) \\
3(7) \\
2(5) \\
0 \\
13(31)\end{array}$ & $\begin{array}{c}6(13) \\
5(11) \\
3(6) \\
1(2) \\
13(28)\end{array}$ & $\begin{array}{c}10(18) \\
6(11) \\
1(2) \\
0 \\
11(20)\end{array}$ & $\begin{array}{l}\text { NS } \\
\text { NS } \\
\text { NS } \\
\text { NS } \\
\text { NS }\end{array}$ & $\begin{array}{l}0 \\
0 \\
0 \\
0 \\
24(51)\end{array}$ & $\begin{array}{l}0 \\
0 \\
0 \\
0 \\
5(55)\end{array}$ & $\begin{array}{l}0 \\
0 \\
0 \\
0 \\
3(20)\end{array}$ & $\begin{array}{l}0 \\
0 \\
0 \\
0 \\
2(14)\end{array}$ & $\begin{array}{l}- \\
\overline{-} \\
\overline{\text { More common in }} \\
\text { subjects }<50 \text { years } \ddagger\end{array}$ \\
\hline
\end{tabular}

${ }^{*} \mathrm{p}<0.05, \quad \nmid \mathrm{p}<0.02, \quad \ddagger \mathrm{p}<0.01$ (Chi-squared test with Yates’ corrections).

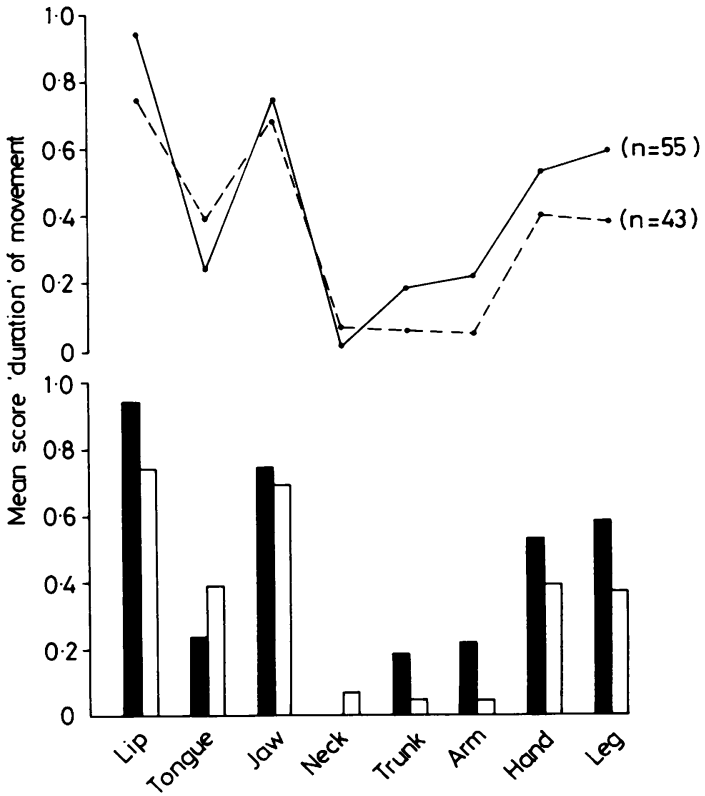

Fig 3 Mean scores for duration of purposeless movements at eight body sites: drug-treated patients over 60 year of age in the furst $(\bigcirc-, \square)$ and second $\left(\bigcirc_{--}, \square\right)$ patient groups.

category was compared in subjects above and below 50 years of age. In the sample of normal subjects there were significantly more subjects below 50 years of age with no significant movement $(p<$ $0 \cdot 01$ ). In the patient group, choreiform movements were significantly more common in patients over 50 years of age $(p<0.02)$.

The presence of oro-facial dyskinesia was determined by one of the authors, (MR) for each of the 267 subjects and, as can be seen from table 3, his

Table 3 Diagnosis of oro-facial dyskinesia by neurologist and rating scale criterion

\begin{tabular}{llrr}
\hline Neurologist's assessment & \multicolumn{3}{l}{$\begin{array}{l}\text { Rating Scale Criterion } \\
\text { Central Score }\end{array}$} \\
& $>2$ & \multicolumn{2}{l}{$\begin{array}{l}\text { Central Score } \\
<2\end{array}$} \\
\hline Oro-facial dyskinesia present & 58 & 14 & 72 \\
Oro-facial dyskinesia absent & 14 & 181 & 195 \\
& 72 & 195 & 267 \\
\hline
\end{tabular}

chi-squared $=143.75, p<0.001$

diagnosis was in close accord with a criterion level of symptomatology derived from the central score (a total of modal scores for movements of the lips, tongue, jaw and neck), (see Barnes and Trauer ${ }^{3}$ ). The results in table 2 show that, for both samples, orofacial dyskinesia was significantly more common in patients over 50 years of age. Oro-facial dyskinesia was significantly more prevalent in patients over 60 years old $(p<0.05)$ and below 39 years of age $(p<$ $0.01)$ compared with the corresponding age-group of normal individuals.

\section{Discussion}

Barnes and Trauer $^{3}$ have previously shown that the central score, a total of scores for lip, tongue, jaw and neck movements, derived using the videotape 
rating technique employed here, corresponds to the clinical assessment of tardive dyskinesia. Clinicians are influenced principally by the severity of orofacial movements in their diagnosis and rating. ${ }^{324}$ Thus the movement profiles for these four body sites in the patient samples may be taken to represent oro-facial dyskinesia. In addition, in the present study, there was an association between a neurologist's diagnosis of oro-facial dyskinesia and a diagnosis made on the basis of the central score (see table 3).

In both psychiatric patients treated with antipsychotic drugs and in drug-naive subjects, the amount of oro-facial movement observed was found to be higher in the older age groups. Twenty percent of untreated subjects over 50 years of age were considered to have oro-facial dyskinesia; a prevalence consistent with that found in surveys of larger but similar samples. ${ }^{14192526}$ However, oro-facial dyskinesia was more common in the psychiatric patients treated with antipsychotic drugs, than in drug-naive subjects. Thus age and antipsychotic drug treatment would appear to be relevant factors in the prevalence and severity of oro-facial dyskinesia; a finding that is consistent with previous reports. ${ }^{27-29}$ The number of non-schizophrenic drug-treated cases was too small for meaningful analysis, so the possibility that oro-facial dyskinesia is related to schizophrenia cannot be excluded.

The central or oro-facial movement profile in the patient sample has the same characteristic pattern in all five age-groups except the lowest (see fig 1). This reinforces the finding by Gerlach ${ }^{30}$ that oro-facial dyskinesia increases in severity with age without any change in the topographic distribution or movement pattern. Similarly, the oro-facial profile in the normal subjects has a characteristic pattern throughout the age-groups. However, the age-adjusted central profile for patients is different from the corresponding profile for normal controls. These two characteristic patterns, derived from ratings of movement in a standard situation, as described, possibly reflect different pathophysiological mechanisms. Whether the differences between the two movement patterns are distinct enough to allow discrimination clinically between the two conditions, remains to be tested.

With regard to the trunk and limb (peripheral) movements rated, when the patterns of movement distribution for the four relevant body sites in the patient sample and normal individuals were compared, they were not different. However, these profiles reflect only the proportion of time the patients manifested purposeless movements. Attention to the nature of these movements is necessary in order to compare the patient and normal subject samples, and to estimate the clinical importance and therapeutic implications of trunk and limb movement problems related to antipsychotic drug administration. The information presented in table 2 indicates that the movements rated in the normal controls were predominantly semi-purposeful or purposeless normal movements; these were more prevalent in the subjects over 50 years of age. Apart from two elderly normal controls who manifest choreiform movements, abnormal movements occurred only in the patient sample. While choreiform movements were more common in patients over 50 years old there was no association between age and the presence of dystonic phenomena or stereotypies and mannerisms. Stereotypies and mannerisms are traditionally associated with a schizophrenic illness and their association with antipsychotic drug treatment is thus doubtful. However, for choreiform movements and dystonias, antipsychotic drug treatment would appear to be an important factor in development. In addition, age may be specifically relevant to the emergence of choreiform movements.

Choreiform movements of the trunk and limbs were seen in $24 \%$ of subjects over 50 years old in the first patient sample. According to Rosen et $a^{24}$ psychiatric patients on maintenance antipsychotic therapy are more likely to be aware of, and distressed by, dyskinesia of the arms and legs, than the presence of oro-facial movements. Dystonic movements or postures were present in $11 \%$ of patients over 50 years old. Chronic or tardive dystonia, developing in association with chronic antipsychotic drug treatment has only recently been recognised ${ }^{31}$ as a potentially disabling and distressing condition which is difficult to treat.

Multivariate statistical analysis of abnormal movements in psychiatric patients receiving chronic antipsychotic medication, has been attempted by Kennedy et al, ${ }^{32}$ Crane $e t a^{33}$ and Kidger et al. ${ }^{22}$ Three general factors, or components, have emerged from these studies: an oro-facial movement factor, a trunk and limb movement factor and a Parkinsonian factor. The clinical validity of distinguishing between the first two factors has been demonstrated by a number of studies where a differential drug response between oro-facial and trunk and limb movements has been noted, ${ }^{34-39}$ although findings have not been sufficiently consistent between studies to allow predictive statements to be made regarding the nature of the response to specific types of drug. A similar differential drug effect has also been reported for idiopathic dyskinesia. Delwaide and Desseilles ${ }^{19}$ concluded that this condition should be considered as two separate subsyndromes, bucco-linguo-facial dyskinesia and "stereotyped movements of the limbs", on the basis 
of their differential sensitivity to antipsychotic drugs. The results of the present study indicate that purposeless oro-facial movements rated in a patient sample represented oro-facial (tardive) dyskinesia. However, purposeless trunk and limb movements were found to comprise a variety of abnormal movements, the precise nature of which would have been obscured by the use of a single descriptive term such as trunk and limb "dyskinesia". As Granacher $r^{40}$ has stated, it may be "necessary to differentiate tardive dyskinesia of the mouth parts from that of axial-limb parts in future studies to more accurately define this syndrome and to prevent the confusion that now exists in most research exploring drug treatment of the disorder". Such considerations may apply equally to the differentiation of trunk and limb dyskinesia into the various normal and abnormal movements which may be present in psychiatric patients treated with antipsychotic drugs.

Thanks are due to Dr T Kidger for access to data from a previous joint study, to Drs DH Roy, RWK Bamber and $G$ Milavic for the videotape ratings, and to Professor CD Marsden for advice and guidance.

\section{References}

${ }^{1}$ Uhrbrand L, Faurbye A. Reversible and irreversible dyskinesia after treatment with perphenazine, chlorpromazine, reserpine and ECT. Psychopharmacol 1960;1:408-18.

${ }^{2}$ Gardos G, Cole JO, La Brie R. The assessment of tardive dyskinesia. Arch Gen Psychiatry 1977;34:120612.

${ }^{3}$ Barnes TRE, Trauer T. Reliability and validity of a tardive dyskinesia videotape rating technique. $\mathrm{Br} J$ Psychiatry 1982;140:508-15.

${ }^{4}$ Faurbye A, Rasch PJ, Petersen PB, Brandborg G, Pattenberg $H$. Neurological symptoms in pharmacotherapy of psychoses. Acta Psychiat Scand 1964;40:10-27.

5 Siede H, Muller HF. Choreiform movements as sideeffects of phenothiazine medication in geriatric patients. J Am Geriat J Soc 1967;22:517-22.

${ }^{6}$ Brandon S, McClelland HA, Protheroe C. A study of facial dyskinesia in a mental hospital population. $B r J$ Psychiatry 1971;118:171-84.

${ }^{7}$ Klawans HL, Bergen D, Bruyn GW. Neurolepticinduced tardive dyskinesias in nonpsychotic patients. Arch Neurol 1974;30:338-9.

${ }^{8}$ Casey DE, Rabins P. Tardive dyskinesia as a lifethreatening illness. Am J Psychiatry 1978;135:486-8.

${ }^{9}$ Amsterdam J, Mendels J. Treatment resistant tardive dyskinesia: A new therapeutic approach. Am J Psychiatry 1979;136:1197-8.

${ }^{10}$ Demars JCA. Neuromuscular effects of long-term phenothiazine medication, electroconvulsive therapy and leucotomy. J Nerv Ment Dis 1966;143:73-9.

"Pryce IG, Edwards H. Persistent oral dyskinesia in female mental hospital patients. Br J Psychiatry 1966;112:983-7.

${ }^{12}$ Degkwitz R, Wenzel W. Persistent extrapyramidal side-effects after long-term application of neuroleptics. In: Brill H, Cole JO, Hippius H and Bradley PB, eds. Neuropsychopharmacology. Amsterdam: Excerpta Medica 1976:608-615 (International Congress series 129).

${ }^{13}$ Appenzeller O, Biehl JP. Mouthing in the elderly. Neurology (Minneap) 1967;17:290.

14 Greenblatt DL, Dominick RN, Stotsky BA, DiMascio A. Phenothiazine-induced dyskinesia in nursing-home patients. J Am Geriatr Soc 1968;16:27-34.

15 Heinrich K, Wegner I, Bender HJ. Späte extrapyramidalen Hyperkinesen bei neuroleptischer Langzeittherapie. Pharmakopsychiatr Neuropsychopharmakol 1968;1:169-95.

${ }^{16}$ Hippius H, Lange J. Zur Problematik der späten extrapyramidalen Hyperkinesen nach langfristiger neuroleptischer Therapie. Arnzeim Forsch 1970;20:888-890.

${ }^{17}$ Crane GE. Persistent dyskinesia. Br J Psychiatry 1973;122:395-405.

${ }^{18}$ Altrocchi PH. Spontaneous oral-facial dyskinesia. Arch Neurol 1972;26:506-12.

19 Delwaide PJ, Desseilles M. Spontaneous buccolinguofacial dyskinesia in the elderly. Acta Neurol Scand 1977;56:256-62.

${ }^{20}$ Marsden CD, Parkes JD. Abnormal movement disorders. Br J Hosp Med 1973;10:428-50.

21 Degkwitz R, Wenzel W. Persistent extrapyramidal side-effects after long-term application of neuroleptics. In: Crane GE and Gardner RJ Jnr, eds. Psychotropic Drugs and Dysfunctions of the Basal Ganglia. Washington, US Public Health Service Publication, no. 1938,$1969 ; 22-32$.

${ }^{22}$ Kidger T, Barnes TRE, Trauer T, Taylor PJ. Subsyndromes of tardive dyskinesia. Psychol Med 1980;10:513-20.

${ }^{23}$ Research Group on Extrapyramidal Disorders of the World Federation of Neurology. Classification of extrapyramidal disorders: proposal for an international classification and glossary of terms. J Neurol Sci 1981;51:311-27.

${ }^{24}$ Rosen AM, Mukherjee S, Olarte S, Varia V, Cardenas C. Perception of tardive dyskinesia in outpatients receiving maintenance neuroleptics. Am J Psychiatry 1982;139:372-3.

${ }^{25}$ Blowers AJ, Borison RL, Blowers CM, Bicknell DJ. Abnormal involuntary movements in the elderly. $\mathrm{Br} \mathrm{J}$ Psychiatry 1981;139:363-4.

${ }^{26}$ Bourgeois M, Boueilh P, Tignol J. Dyskinésies spontanées sénile idiopathiques et dyskinésies tardives des neuroleptiques. L'Encéphale 1980;VI:37-9.

${ }^{27}$ Tepper SJ, Haas JF. Prevalence of tardive dyskinesia. J Clin Psychiatry 1979;40:508-16.

${ }^{28}$ Smith JM, Baldessarini RJ. Changes in prevalence, severity and recovery in tardive dyskinesia with age. Arch Gen Psychiatry 1980;37:1368-73.

${ }^{29}$ Barnes TRE, Kidger T, Gore SM. Tardive dyskinesia: a 
3-year follow-up study. Psychol Med 1983 (in press).

${ }^{30}$ Gerlach J. Relationship between tardive dyskinesia, 1-dopa-induced hyperkinesia and Parkinsonism. Psychopharmacol 1977;51:259-63.

${ }^{31}$ Burke RE, Fahn S, Jankovic J, Marsden CD, Lang AE, Gollom S, Ilson J. Tardive dystonia and inappropriate use of neuroleptic drugs. Lancet 1982,i:1299.

${ }^{32}$ Kennedy P, Hershon H, McGuire R. Extrapyramidal disorders after prolonged phenothiazine therapy. $\mathrm{Br} J$ Psychiatry 1971;118:509-18.

${ }^{33}$ Crane GE, Naranjo ER, Chase C. Motor disorders induced by neuroleptics-A proposed new classification. Arch Gen Psychiatry 1971;23:179-84.

${ }^{34}$ Fann WE, Lake CR, Gerber CJ, McKenzie GM. Cholinergic suppression of tardive dyskinesia. Psychopharmacologia (Berl) 1974;37:101-7.

${ }^{35}$ Gardos G, Cole JO, Sniffin C. An evaluation of papaverine in tardive dyskinesia. J Clin Pharmacol 1976;16:304-10.

${ }^{36}$ Casey DE, Denney D. Pharmacological characterisation of tardive dyskinesia. Psychopharmacol 1977;54:1-9.
${ }^{37}$ Simpson GM Voitashevsky A, Young MA, Lee JH. Deanol in the treatment of tardive dyskinesia. Psychopharmacol 1977;52:257-61.

${ }^{38}$ Casey DE, Hammerstad JP. Sodium valproate in tardive dyskinesia. J Clin Psychiatry 1979;40:483-5.

${ }^{39}$ Bobruff A, Gardos G, Tarsy D, Rapkin RM, Cole JO, Moore P. Clonazepam and phenobarbital in tardive dyskinesia. Am J Psychiatry 1981;138:189-93.

${ }^{40}$ Granacher RP. Differential diagnosis of tardive dyskinesia: an overview Am J Psychiatry 1981;138:1288-97.

${ }^{41}$ Davis JM. Dose equivalence of the antipsychotic drugs. $J$ Psychiat Res 1974;11:65-9.

42 Wyatt RJ, Togrow JS. A comparison of equivalent clinical potencies of neuroleptics as used to treat schizophrenia and affective disorders. J Psychiat Res 1976;13:91-8.

${ }^{43}$ Ellenor GL. Reducing irrational antipsychotic polypharmacy prescribing. Hosp Pharmacology 1977;12:369-76. 